\title{
(I)MOBILIDADE E TÁTICAS ESPACIAIS NO QUOTIDIANO DE PESSOAS EM SITUAÇÃO DE SEM TETO: O CASO DO PORTO, PORTUGAL
}

\section{- JOÃO SARMENTO 1}

Doutor em Geografia pela Universidade de Cork, Irlanda. Professor no Instituto de Ciências Sociais da Universidade Minho e Investigador no Centro de Estudos de Comunicação e Sociedade da Universidade do Minho. E-mail para contato: j.sarmento@geografia.uminho.pt

\section{- JORGE LEÃO ${ }^{2}$}

Mestre em Geografia pela Universidade do Minho. Mestrando em Ensino de Geografia na Universidade do Porto. Email para contato: jorgecleao@gmail.com

Recebido em:10/07/2020

Aprovado em: 22/01/2021

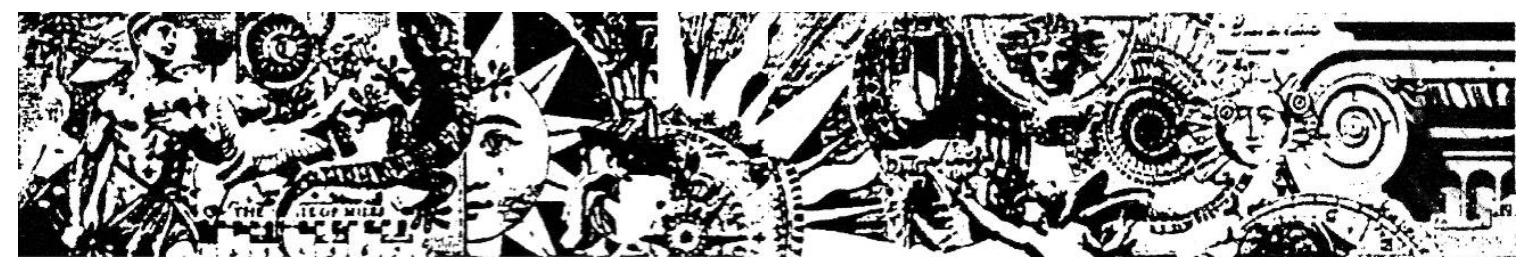

Resumo: 0 mobility turn nas ciências sociais e humanas, recentrou o movimento como dimensão fundamental para a vida. Paradoxalmente, embora em abstrato pessoas em situação de sem teto tenham autonomia de uma localização espacial fixa para moradia, no concreto elas apresentam grandes dificuldades de movimento, e uma dificuldade em tirar partido dos benefícios de viver em cidades. Este artigo analisa a espacialidade de pessoas em situação de sem teto na cidade do Porto, Portugal. A pesquisa partiu de informação recolhida junto de prestadores de serviços que trabalham no terreno, da observação detalhada de um conjunto de ruas no centro da cidade, e de várias conversas com um conjunto de pessoas em situação de sem teto. São apontados cinco argumentos principais: as pessoas em situação de sem teto (i) têm uma grande imobilidade espacial; (ii) moram numa área muito confinada da cidade; (iii) têm rotinas espaciais específicas que governam rigidamente o seu quotidiano; (iv) têm rotinas espaciais principalmente 
ditadas pela lógica dominante dos "fornecedores de sopa"; (v) têm uma agência, por meio da qual estabelecem uma miríade de laços sociais baseados na confiança e na amizade.

Palavras-Chave: Sem teto; (I)mobilidade; Visibilidade; Estratégias espaciais; Porto.

(I) MOBILITY AND SPATIAL TACTICS IN THE EVERYDAY LIFE OF PEOPLE IN A HOMELESS SITUATION: THE CASE OF PORTO, PORTUGAL

\begin{abstract}
THE MOBILITY TURN IN THE SOCIAL AND HUMAN SCIENCES HAS BROUGHT MOVEMENT BACK INTO FOCUS AS A CRITICAL DIMENSION OF LIFE. PARADOXICALLY, ALTHOUGH IN ABSTRACT TERMS, PEOPLE IN A HOMELESS SITUATION ARE INDEPENDENT FROM FIXED SPATIAL LOCATIONS FOR HOUSING, IN PRACTICE, THEY HAVE GREAT MOVEMENT RESTRICTIONS, AND A DIFFICULTY IN TAKING ADVANTAGE OF THE BENEFITS OF LIVING IN CITIES. THIS ARTICLE ANALYSES THE SPATIALITY OF PEOPLE IN A HOMELESS SITUATION IN THE CITY OF PORTO, PORTUGAL. THE RESEARCH STARTED FROM INFORMATION COLLECTED FROM SERVICE PROVIDERS WORKING IN THE FIELD, FROM DETAILED OBSERVATION OF A SET OF STREETS IN THE CITY CENTRE, AND FROM SEVERAL CONVERSATIONS WITH A GROUP OF PEOPLE IN A HOMELESS SITUATION. FIVE MAIN ARGUMENTS ARE POINTED OUT: PEOPLE IN A HOMELESS SITUATION (I) HAVE A STRONG SPATIAL IMMOBILITY; (II) LIVE IN A VERY CONFINED AREA OF THE CITY; (III) HAVE SPECIFIC SPATIAL ROUTINES THAT RIGIDLY GOVERN THEIR DAILY LIVES; (IV) HAVE SPATIAL ROUTINES MAINLY DICTATED BY THE GOVERNING LOGIC OF "SOUP RUNS"; (V) HAVE AN AGENCY, THROUGH WHICH THEY ESTABLISH A MYRIAD OF SOCIAL TIES BASED ON TRUST AND FRIENDSHIP.
\end{abstract}

KEYWORDS: HOMELESS, (I)MOBILITY, VISIBILITY, SPATIAL STRATEGIES, PORTO

\title{
(I) MOVILIDAD Y TÁCTICAS ESPACIALES EN EL DÍA DÍA DE LAS PERSONAS EN SITUACIÓN SIN HOGAR: EL CASO DEL PORTO, PORTUGALTÍTULO EM ESPANHOL
}

RESUMEN: EL GIRO DE LA MOVILIDAD EN LAS CIENCIAS SOCIALES Y HUMANAS HA VUELTO A PONER DE RELIEVE EL MOVIMIENTO COMO UNA DIMENSIÓN FUNDAMENTAL DE LA VIDA. PARADÓJICAMENTE, AUNQUE EN ABSTRACTO LAS PERSONAS EN SITUACIÓN DE DESAMPARO TIENEN AUTONOMÍA DE UNA UBICACIÓN ESPACIAL FIJA PARA LA VIVIENDA, EN CONCRETO TIENEN GRANDES DIFICULTADES DE MOVIMIENTO Y DIFICULTAD PARA APROVECHAR LOS BENEFICIOS DE VIVIR EN LAS CIUDADES. ESTE ARTÍCULO ANALIZA LA ESPACIALIDAD DE LAS PERSONAS SIN HOGAR EN LA CIUDAD DEL PORTO, PORTUGAL. LA INVESTIGACIÓN PARTIÓ DE LA INFORMACIÓN RECOPILADA DE LOS PROVEEDORES DE SERVICIOS QUE TRABAJAN EN EL CAMPO, DE LA OBSERVACIÓN DETALLADA DE UN CONJUNTO DE CALLES EN EL CENTRO DE LA CIUDAD Y DE VARIAS CONVERSACIONES CON UN GRUPO DE PERSONAS SIN HOGAR. SE SEÑALAN CINCO ARGUMENTOS PRINCIPALES: LAS PERSONAS SIN HOGAR (I) TIENEN UNA GRAN INMOVILIDAD ESPACIAL; (II) VIVIR EN UNA ZONA MUY RESTRINGIDA DE LA CIUDAD; (III) TIENEN RUTINAS ESPACIALES ESPECÍFICAS QUE RIGEN RÍGIDAMENTE SU VIDA DIARIA; (IV) TIENEN RUTINAS ESPACIALES DICTADAS PRINCIPALMENTE POR LA LÓGICA DOMINANTE DE LOS 
"PROVEEDORES DE SOPA"; (V) TIENEN UNA AGENCIA, A TRAVÉS DE LA CUAL ESTABLECEN UNA MIRÍADA DE VÍNCULOS SOCIALES BASADOS EN LA CONFIANZA Y LA AMISTAD.

PALABRAS CLAVE: SIN TECHO; (I)MOVILIDAD; VISIBILIDAD; ESTRATEGIAS ESPACIALES; PORTO.

\section{Os sem teto: táticas e (i)mobilidade}

A natureza da ausência de teto pode assumir diversas condições. Pode incluir pessoas que vivem em (i) locais precários, como sejam edifícios devolutos, vãos de escadas ou entradas de prédios ou espaços comerciais; (ii) abrigos de emergência, de natureza provisória e de acolhimento imediato, geralmente em articulação com organizações de segurança social; ou simplesmente (iii) na rua, em espaços públicos, como jardins, estações de transporte, passeios, viadutos ou túneis. Se a estas três condições juntarmos todas aquelas pessoas que não têm casa e vivem em centros de alojamento temporário ou pensões ou quartos pagos por serviços sociais, chegamos uma tipologia de pessoas em condição de sem abrigo. Nesta investigação incidimos espacialmente sobre pessoas em situação de sem teto, a viver na rua ou espaço público, se bem que diversas estatísticas aqui usadas se refiram a pessoas em situação de sem abrigo.

Numerosos trabalhos mostram como o Estado, as organizações não governamentais (ONGs), a igreja e a sociedade civil, têm múltiplas respostas à falta de moradia por parte (SHEEHAN, 2010). Ao mesmo tempo, como Snow e Mulcahy (2001, p.154) argumentam, "para entender o caráter da vida nas ruas dos sem teto em qualquer comunidade, é imperativo entender a variedade que afeta as rotinas diárias e atividades de subsistência dos sem teto". Em consonância, Deverteuil et al (2009, p.661) têm defendido pesquisas que se envolvam "mais diretamente com os autores reais dessas geografias de sem teto", enquanto Cloke, May e Johnsen (2010) defendem uma caracterização da falta de moradia que preste mais atenção à agência dos próprios sem teto. Neste artigo, queremos sugerir que há muito a aprender com a observação e com o envolvimento nas rotinas diárias das pessoas em situação de sem teto. É apenas observando em detalhe as suas geografias, que podemos compreender como as cidades são lugares onde diferentes temporalidades de ação entram em atrito (SASSEN, 1999).

No seu trabalho seminal A prática da vida cotidiana, De Certeau (1984) fez uma distinção entre estratégias e táticas. Visto dos círculos militares, as táticas são subordinadas às estratégias; elas são meras técnicas moldadas por decisões maiores e mais críticas relacionadas a objetivos gerais. Ainda assim, De Certeau entendia as estratégias e táticas como duas forças opostas. As primeiras estão relacionadas com 
estruturas disciplinares urbanas que formam a base para a geração de relações e são controladas pelos poderosos. As segundas podem ser entendidas como liberdades construídas pelos não-poderosos e dependem da 'arte do tempo', exigindo que as pessoas estejam "atentas às oportunidades que devem ser 'aproveitadas"” (DE CERTEAU, 1984: xix). As táticas são ações em permanente estado de reavaliação e correção, constantemente baseadas em observações do ambiente real. Elas implicam navegar num ambiente urbano hostil e, de certa forma, constituem uma forma de resistência. Cloke, May e Johnsen (2008) enquadraram o seu trabalho nos "estranhos mapas" da vida da cidade realizados por pessoas em condição de sem teto, precisamente com base nas estratégias e táticas de De Certeau. Estes autores concentraram-se nas "estratégias pelas quais os espaços dos sem teto são disciplinados e contidos, e as táticas implantadas por pessoas sem teto para negociar essa contenção" (CLOKE, MAY e JOHNSEN, 2008: 246). A ideia de tática, inicialmente conceptualizada por De Certeau como uma ordem espacial que organiza um conjunto de possibilidades e interdições, é útil para pensar as formas como as pessoas em condição de sem teto tentam contornar aquilo que percebem ser dificuldades. Os "estranhos mapas" da vida na cidade não se conformam com o que tem vindo a ser denominado de "era da mobilidade", um tempo e espaço em que aparentemente vivemos e que domina as "nossas" vidas: transportes velozes de alcance global, redes de informação complexas, comunicação atualizada ao segundo, e assim por diante. Muitas pessoas agora podem viajar para longe, em pouco tempo e com custos relativamente baixos, sendo que o movimento perpétuo faz parte de quem somos e do que fazemos (CRESSWELL, 2001). As cidades, em particular, investem fortemente em infraestruturas de mobilidade, desde cabos de fibra ótica, túneis de metro, viadutos ou inteligência artificial que permita maior velocidade. Na verdade, somos constantemente lembrados de que as cidades são movimento, são contato, predominando os fluxos de capital e pessoas.

A centralidade contemporânea da mobilidade nas nossas vidas foi reconhecida nas ciências sociais, levando Sheller e Urry (2006: 207), entre outros autores, a defender a existência de um "novo paradigma". Esta mudança paradigmática destacou a mobilidade como fundamental para a vida contemporânea, mobilidade essa que permeia todos os aspetos do mundo contemporâneo, tendo uma ampla gama de significados, práticas e políticas, sejam elas relacionadas com o caminhar, com deslocações quotidianas ou com o viajar. No entanto, como Cresswell (1996) sublinhou, a mobilidade pode ser entendida como uma transgressão das fronteiras de geografias que temos enraizadas. 
Pode funcionar como uma espécie de "super desvio" ou deriva que desassossega as noções de que o mundo pode ser segmentado em lugares claramente definidos. Contrastando com a ordem obtida pela divisão do espaço, a desordem e o caos podem ser criados pela mobilidade, o que pode contribuir para a transgressão e a invasão. Cresswell (2001) acrescenta que não é por acaso que o controle da mobilidade é uma prioridade daqueles que têm interesse em manter sua própria definição de ordem.

Há quase trinta anos, Neil Smith (1992) argumentou que em grande medida a falta de mobilidade era responsável pela invisibilidade das pessoas em condição de sem teto. O seu estudo sobre o homeless vehicle, analisou como um projeto artístico e de ativismo político permitia a um número limitado de pessoas em condição de sem teto, dar um salto de escala na cidade, circular mais livremente e guardar os seus objetos pessoais. O projeto pretendia desestabilizar o status quo da ordem espacial na cidade, ao tornar algumas pessoas em condição de sem teto não só mais visíveis no espaço público, mas também mais móveis. Wolch et al. (1993) mostraram como a localização dos serviços de apoio das pessoas em condição de sem teto (assistência médica, serviços de distribuição de alimentos e roupas, etc.) tende a condicionar e moldar as suas próprias geografias. Mais recentemente, num estudo sobre pessoas em condição de sem teto em Long Beach, nos Estados Unidos da América, Jocoy e Del Casino (2011: 1952) concluíram que "adultos sem teto percorrem distâncias mais curtas por viagem e por dia do que a população em geral e do que as famílias urbanas mais pobres, mas fazem um número um pouco superior de viagens por dia. Os sem teto viajam metade das milhas por dia do que as famílias urbanas na população em geral, e menos milhas do que as famílias urbanas mais pobres, vivendo assim vidas menos móveis e mais restritas geograficamente".

Vários académicos concordam que a cidade neoliberal foi parcialmente responsável pelo agravamento das desigualdades socioeconómicas e pela exclusão de grupos marginalizados (MITCHELL, 2003; SMITH, 1996; MACLEOD, 2002). Com o ganho de terreno da cidade empreendedora, do "renascimento" do centro, da gentrificação, proliferaram os sistemas de vigilância ativa e a disciplina urbana, frequentemente através de formas e projetos arquitetónicos e práticas institucionais. Vinda especialmente da América do Norte, a ideia de que a distribuição desigual dos benefícios da globalização está a criar paisagens de poder (ZUKIN, 1991), alimenta a noção de uma natureza cada vez mais bipolar da cidade contemporânea. Por um lado, vemos a reprodução de espaços para os poderosos - enclaves hermeticamente fechados, 
condomínios fechados, centros comerciais vigiados e seletivos (SIBLEY, 1995; SMITH, 1996) - e espaços para os despossuídos - zonas demarcadas sem interesse imobiliário, áreas carentes e decadentes. Com base em exemplos de Los Angeles, essa bipolarização da cidade contemporânea deu origem a políticas de exclusão e contenção (DAVIS, 1992), a uma "mudança punitiva" (DEVERTEUIL et al 2009), e ao revanchismo urbano (SMITH, 1996). Esses processos e tendências não são rígidos e estáticos (HODGETTS et al, 2008) e divergem significativamente de um contexto para outro, tendo vários graus de intensidade. Mas eles chocam com a luta diária das pessoas em condição de sem teto em manter os direitos mais básicos, como simplesmente estar no espaço público (HODGETTS et al, 2008; MITCHELL, 2003).

Neste artigo, pretendemos olhar para a complexidade das geografias das pessoas em condição de sem teto numa cidade particular. Começamos por mapear e tentar compreender os movimentos espaciais e a amplitude de uma amostra de pessoas em condição de sem teto. À semelhança de muitas outras cidades ocidentais, a condição de sem abrigo em Portugal tornou-se mais grave na última década, tendo sido acompanhada pela crise financeira de 2008-2014, e mais recentemente pela pandemia do Covid-19. O fenómeno limita-se, principalmente, às grandes cidades, e é mais evidente nas áreas urbanas centrais. Argumenta-se aqui que as pessoas em condição de sem teto vivem numa área muito confinada da cidade e que essa geografia é moldada por uma variedade de fatores: a localização dos vários serviços de apoio às pessoas em condição de sem teto, as barreiras existentes, a falta de mobilidade e as estratégias pessoais e tomadas de decisão. As informações foram obtidas em instituições que trabalham no terreno, observações detalhadas na rua e várias conversas com pessoas em condição de sem teto. O restante deste artigo está organizado em cinco secções. A primeira oferece uma discussão das ideias de mobilidade, falta de habitação e as transformações da cidade ocidental contemporânea. A segunda descreve o processo metodológico seguido nesta pesquisa. A terceira secção apresenta a cidade do Porto e caracteriza o grupo de pessoas em condição de sem teto no país e nesta cidade em particular, destacando os prestadores de serviços às pessoas em condição de sem teto. A quarta secção discute 12 experiências de pessoas em condição de sem teto no Porto, analisando as suas atividades e padrões da vida quotidiana. A última secção apresenta as principais conclusões do estudo. 


\section{Metodologia}

Utilizamos uma metodologia em cinco etapas. Em primeiro lugar, estabeleceuse contacto com as várias instituições que prestam assistência às pessoas em condição de sem teto no Porto, e estudaram-se as suas práticas e abordagem espacial às pessoas em condição de sem teto na cidade. Em segundo lugar, participamos do trabalho voluntário de distribuição de alimentos e roupas ou oferta de comida na rua - também às vezes descrito como "Soup runs" (ver JOHNSEN, CLOKE e MAY, 2005), durante um curto período de tempo, ou seja, 30 rondas corridas, ou 30 noites. Esta ação permitiu-nos adquirir uma visão particular sobre os processos que se desenrolam quando voluntários encontram pessoas em condição de sem teto por um tempo limitado em vários locais da cidade (Fig. 1), e um contato mais próximo com os moradores de rua, e também com alguns dos voluntários que prestam esse atendimento. Dessas 30 rondas noturnas, 6 foram realizadas no veículo da instituição e, por falta de lugar, 24 foram realizadas acompanhando esse veículo num carro particular. Esta participação deu origem à terceira etapa metodológica, que consistiu em identificar duas áreas concretas (de cinco iniciais) do centro da cidade, que foram escolhidas tendo em consideração o número de pessoas em condição de sem teto encontradas e a assistência prestada pelas instituições. Em quarto lugar, foram realizadas, de fevereiro a junho de 2013, 80 caminhadas (80 dias) de observação nessas duas áreas (Fig. 2), a fim de mapear e estabelecer contatos informais e preliminares com os moradores de rua, uma prática em tudo semelhante à "etnografia de rua" (URRY e BUSCHER, 2009). Estas caminhadas de levantamento, que duravam cerca de 90 minutos na área $\mathrm{A}$, e cerca de 120 minutos na área $\mathrm{B}$, não tinham como objetivo travar qualquer conversa com moradores de rua, mas tinham um duplo propósito. Por um lado, permitirem que os pesquisadores fossem vistos por pessoas em condição de sem teto regularmente, para se tornarem lentamente visíveis e possivelmente confiáveis, e por outro lado serviram para mapear os locais específicos em que os moradores de rua habitavam. Como a distribuição de alimentos e roupas geralmente ocorre após as $21 \mathrm{~h}$, todas as caminhadas foram feitas a partir das $23 \mathrm{~h} 30$, o que permitiu um mapeamento mais preciso. Por fim, utilizando uma amostra por conveniência, foi estabelecido contato com 12 pessoas em condição de sem teto. Esta amostra incide numa parcela específica desta população, ou seja, aqueles que não utilizam abrigo institucional para pernoite e devem buscar refúgio nas ruas da cidade. Ao longo 
de quatro meses, de breves conversas e poucas palavras trocadas, os encontros evoluíram para várias conversas informais, que duraram de 5 a 40 minutos.

\section{A pessoas em situação de sem teto no Porto, Portugal}

Ainda que tenha havido uma melhoria entre 2014 e 2019, Portugal tem um dos níveis mais elevados de risco de pobreza ou exclusão social entre os Estados-Membros da União Europeia (2 1,6\% em 2019). No ano de 2020, por causa da pandemia, a situação agravou-se. No contexto deste trabalho, cuja parte empírica foi realizada durante o ano de 2013, importa notar que o período de análise decorreu durante o resgate financeiro da troika - Fundo Monetário Internacional, Banco Central Europeu, e Comissão Europeia (2011-2014). Este período caracterizou-se por uma série de medidas de austeridade, incluindo a redução de salários, o congelamento de pensões e o aumento da tributação, o que em conjunto ampliaram a desigualdade, atingindo mais os pobres (BAPTISTA, 2013). Exemplo disso são os relatórios da AMI (Assistência Médica Internacional) sobre o número de pessoas sem abrigo que acederam aos seus serviços em Portugal, que aumentou mais de 25\% em apenas 4 anos: $1.448 \mathrm{em} 2007$ e $1.815 \mathrm{em} 2011$. Chocando com esta realidade, está, em sociedades neoliberais, o entendimento da habitação como um bem e mercadoria (HARVEY, 2004), e a fragilidade do entendimento da habitação como direito fundamental. Paradoxalmente, as políticas macroeconómicas que levaram ao crédito barato para aquisição de habitação, beneficiaram uma classe média-alta, e resultaram na superprodução de casas, muitas delas vazias e destinadas ao investimento.

Antes de considerarmos as experiências e mobilidade das pessoas em situação de sem teto, é importante apresentar brevemente a cidade do Porto, Portugal. Situada no norte do país, é uma cidade histórica, com um centro classificado de património mundial da UNESCO. Com 214.349 habitantes (2016), é o centro de uma área urbana metropolitana com cerca de 1,7 milhões de habitantes. Desde a década de 1980 a população da cidade vem diminuindo, tendo perdido, de 1980 até 2016, cerca de 100 mil habitantes. Em algumas freguesias centrais e orientais, a perda foi de cerca de metade da sua população, ao passo que em várias freguesias centrais, mais de um quarto dos habitantes têm mais de 65 anos. O número de edifícios muito degradados ou a necessitar de grandes obras diminuiu de 2001 para 2011, mas ainda representavam 6,9\% do total de edifícios, sendo que em algumas freguesias centrais ultrapassa os 10\% (INE, 2014). A 
percentagem de edifícios devolutos $(18,8 \%)$ é superior à média do país $(12,6 \%)$, atingindo valores superiores a 30 ou $40 \%$ em algumas freguesias do centro (INE, 2011).

Ao mesmo tempo, a cidade é um destino turístico importante e em franca expansão (até início de março de 2020), e a reabilitação urbana é sobretudo articulada ou direcionada para os interesses do capital financeiro global. Olhando para o último censo estatístico (2011), o Porto tinha "apenas" 146 pessoas sem abrigo. No entanto, os números da Segurança Social para esse mesmo ano - e estes são apoiados por um trabalho muito mais próximo no terreno - apontam para 1113. De acordo com a Segurança Social, em 2014 havia 5000 sem abrigo em Portugal, e um estudo de janeiro de 2016 revela que existiam 1600 sem abrigo só na cidade do Porto. Os números do Núcleo de Planeamento e Intervenção aos Sem Abrigo do Porto (NPISA-Porto) indicavam cerca de 2.000 sem abrigo (400 a viver em casas abandonadas, 1500 em soluções provisórias de segurança social como nas pensões e cerca de 100 na rua). Ainda que os dados empíricos deste estudo remetam para 2013, em plena crise financeira, importa aflorar o que se passou desde então. Em fevereiro de 2019, a segurança social reportava 696 pessoas em situação de sem abrigo, das quais 174 em situação de sem teto. Depois do início da pandemia registaram-se quebras acentuadas nos voluntários de rua, e nas rondas feitas na cidade, sendo que o número de refeições entregues semanalmente cai também. De 2009 a 2015, a Estratégia Nacional de Integração de Pessoas em Situação de Rua, promoveu a implementação e coordenação de grupos locais (ver BAPTISTA, 2013). A estratégia nacional nunca teve orçamento e foi implementada com doações de parceiros. Entretanto, em 2016, foi aprovada uma estratégia local pela Câmara Municipal do Porto, com um orçamento de 200 mil euros, visando a constituição de uma equipa profissional de rua e de uma rede de restaurantes sociais, que pretendem substituir os "fornecedores de sopa" existentes. Foi instalado um abrigo provisório de emergência para 30 pessoas e foi inaugurado o primeiro restaurante social na Batalha, em setembro de 2016. Em 2017, foi aprovada uma nova Estratégia Nacional para a Integração das Pessoas em Situação de Sem Abrigo 2017-2023.

\section{Prestadores de serviços de sem abrigo no Porto}

Como já mencionado, há mais de vinte anos Wolch et al. (1993) estabeleceram uma relação direta entre os lugares onde os serviços de apoio às pessoas em situação de sem teto atuam, e as geografias destas mesmas pessoas. No Porto, as estratégias institucionais moldam os "estanhos mapas". Reunimo-nos com diversas organizações 
que lidam com o fenómeno: Albergues Noturnos do Porto (Abrigos Noturnos do Porto), AMI (Assistência Médica Internacional) e Instituto de Segurança Social. Um estudo realizado por esta última instituição revelou que no Porto, $62 \%$ das pessoas em situação de sem abrigo são do sexo masculino, têm entre os 20-50 anos, a maioria é divorciada, com baixo nível de estudos, sendo maioritariamente da região do Porto. Algumas estão desempregadas há muitos anos e, em muitos casos, os rendimentos muito baixos resultam de pensões de invalidez ou do salário de inserção social. Mais da metade tem problemas de saúde. Participamos em 30 rondas noturnas organizadas pela Escola Nossa Senhora do Rosário, que tem um dos mais antigos projetos de ação social. São rondas semelhantes às organizadas por outros grupos seculares e religiosos (tabela 1). Oito voluntários distribuíram alimentos, roupas e passaram algum tempo com as pessoas em situação de sem abrigo, em locais pré-determinados da cidade. Estas rondas tiveram uma duração entre 3 e 6 horas, incluindo 3 a 10 paragens de duração variável. A duração destas paragens variou entre 15 minutos e uma hora, dependendo de uma ampla gama de fatores: o número de pessoas, a sua disposição para conversar, o estado do tempo, a disponibilidade dos voluntários e o número de paragens a fazer no dia.

\begin{tabular}{|l|c|c|c|}
\hline Nome & Religiosa & Início & $\begin{array}{c}\text { Rondas } \\
\text { semanais }\end{array}$ \\
\hline Colégio Nossa Senhora do Rosário - PAS & Sim & 1998 & 4 \\
\hline $\begin{array}{l}\text { Associação Adventista para o } \\
\begin{array}{l}\text { Desenvolvimento, } \\
\text { Recursos e Assistência }\end{array}\end{array}$ & Sim & 2001 & 1 \\
\hline Centro Cristão da Cidade & Sim & 2002 & 2 \\
\hline Centro de Apoio aos Sem-Abrigo & Não & 2002 & 7 \\
\hline $\begin{array}{l}\text { Famílias, Aldeias e Sem-abrigo Rondas } \\
\text { (FAZ) }\end{array}$ & Sim & 2003 & 1 \\
\hline Franjas Sociais & Sim & 2006 & 1 \\
\hline Fundação AXA & Não & 2007 & 1 \\
\hline Existe + Mundo & Não & 2010 & 2 \\
\hline Ronda dos Sem-Abrigo & Sim & 2010 & 1 \\
\hline Amigos dos Amigos da Rua & Não & 2011 & 1 \\
\hline Amor Perfeito & Não & 2012 & 1 \\
\hline Coração da Rua & Não & 2012 & 1 \\
\hline Abraço na Noite & Não & 2013 & 1 \\
\hline Porta Solidária & Sim & 2013 & 5 \\
\hline
\end{tabular}

Tabela 1: Organizações voluntárias relacionadas com pessoas em situação de sem abrigo no Porto Fonte: Elaborado pelos autores, 2020. 
Baptista (2013: 101) argumentou que "o setor português dos prestadores de serviços para os sem abrigo é caracterizado por uma grande dispersão de organizações, opera de formas muito diferentes e baseia-se em diversas filosofias organizacionais”. Em consequência do que nos parecia uma sobreposição de ações e serviços prestados (no tempo e no espaço), mapeamos os percursos e paragens de todos os grupos de voluntários que fazem este tipo de rondas. Como não foi possível levantar informações diretamente de todos os grupos, solicitamos ao G.A.S.Porto, Grupo de Ação Social, a coleta das mesmas. A Figura 1 ilustra a geografia de todos os locais onde é prestada assistência no período de uma semana. Um aspeto bem visível, e que se destacou nas rondas que efetuamos, é a sobreposição no espaço e no tempo de paragens em vários pontos do centro da cidade. Também foi possível observar que poucos locais estão localizados na periferia da cidade, onde algumas pessoas em situação de sem abrigo foram identificadas.

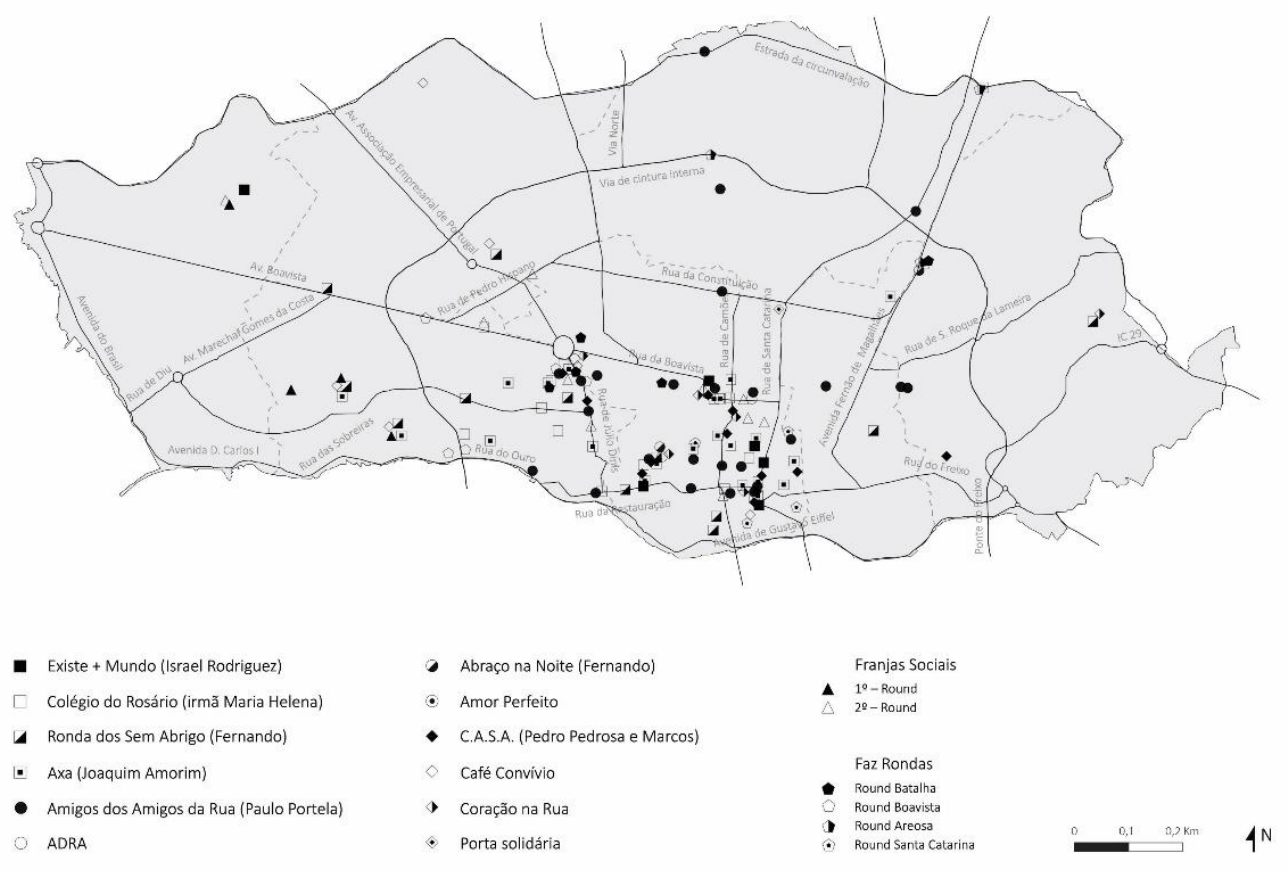

Figura 1: Geografia das organizações voluntárias no Porto Fonte: Rui Pereira, 2020.

\section{Caminhadas de exploração}

Numa fase inicial, procuramos identificar ruas onde pessoas em situação de sem teto fossem visíveis. Após dois meses iniciais de exploração (67 dias) e 40 caminhadas 
realizadas nas áreas A e B, foi possível definir dois percursos pedonais principais, tal como referido. Este processo permitiu adquirir uma ideia precisa dos locais e do número de pessoas em situação de sem teto, ao longo de ambas as rotas (Fig. 2). À exceção da rua Júlio Dinis, onde oito grandes entradas de edifícios e lojas acolhiam em média 10 pessoas em situação de sem teto, todos os outros locais tinham em média 1 a 4 pessoas. Muitos destes locais tinham espaço apenas para uma pessoa, e na maioria das situações, os locais eram limpos meticulosamente antes de serem usados, às vezes com água e vassouras.
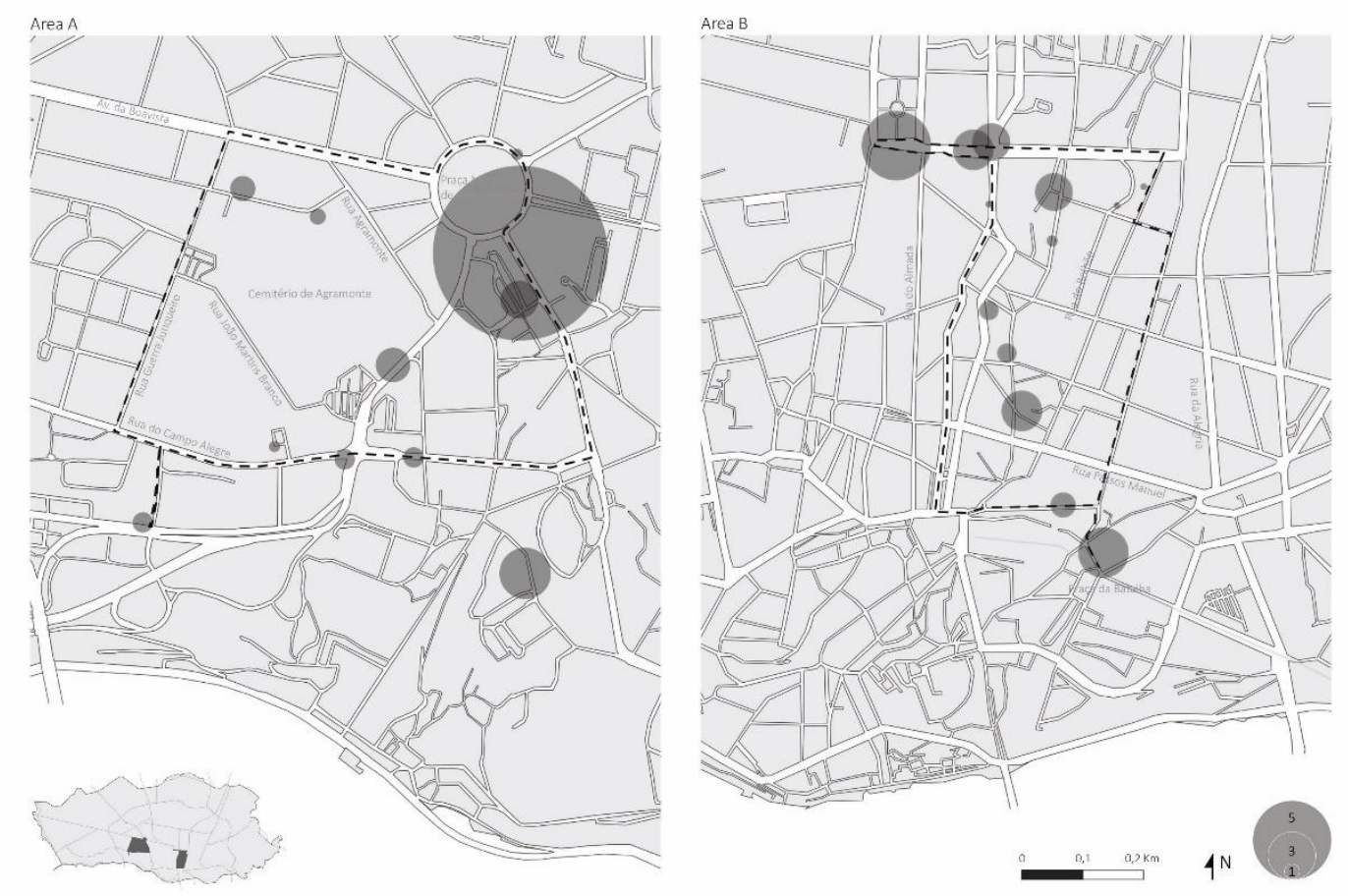

Figura 2: Caminhadas de exploração e número de pessoas em situação de sem abrigo Fonte: Rui Pereira, 2020.

\section{Doze experiências}

Durante a última fase das caminhadas de levantamento registaram-se já múltiplas trocas de olhares, palavras e registaram-se algumas interações verbais: "tem um cigarro?”, “tem luz?', “tem algum dinheiro?”, “tem algo para comer?”, “tem sabonete, pasta de dentes?", e ocasionalmente, "Você de novo?”. Iniciamos conversas regulares com 12 pessoas (tabela 2 ), que compuseram a nossa amostra, obtida por conveniência (nove 
pessoas recusaram conversar). Apenas 1 das 12 pessoas com quem falamos é do sexo feminino, o que em parte reflete a maior invisibilidade das mulheres em situação de sem teto, e também o facto de o pesquisador no terreno ser homem. Embora a representatividade não tenha sido central neste estudo, considerando que em 2013 existiam aproximadamente 100-120 pessoas em situação de sem teto na cidade, esta amostra corresponde a cerca de $10 \%$ do total da população, enquadrando-se na categoria de “moradores de rua há muito tempo" (tabela 2), categoria usada por Sheehan (2010).

\begin{tabular}{|c|c|c|c|c|c|c|c|c|}
\hline Nome & Idade & $\begin{array}{c}\text { Anos } \\
\text { como } \\
\text { sem } \\
\text { teto }\end{array}$ & Origem & $\begin{array}{c}\text { Profissão } \\
\text { anterior }\end{array}$ & $\begin{array}{c}\text { Última } \\
\text { saída } \\
\text { do } \\
\text { Porto } \\
\text { (ano) }\end{array}$ & Razão & $\begin{array}{c}\text { Lugar } \\
(\mathrm{km})\end{array}$ & $\begin{array}{c}\text { Distân } \\
\text { cia } \\
\text { diária } \\
\text { mais } \\
\text { longa } \\
(\mathrm{km})\end{array}$ \\
\hline António & 50 & 20 & Alijó & Médico & 2014 & $\begin{array}{l}\text { Funeral da } \\
\text { mãe }\end{array}$ & $\begin{array}{l}\text { Alijó } \\
(130)\end{array}$ & 3 \\
\hline Augusto & 43 & 2 & Penafiel & Cozinheiro & 2008 & $\begin{array}{c}\text { Entrevista } \\
\text { trabalho }\end{array}$ & $\begin{array}{c}\text { Braga } \\
(50)\end{array}$ & 0,8 \\
\hline Francisco & 41 & 1 & Ovar & $\begin{array}{c}\text { Empregado } \\
\text { de Fábrica }\end{array}$ & 2011 & $\begin{array}{c}\text { Visita } \\
\text { familiares }\end{array}$ & $\begin{array}{l}\text { Ovar } \\
(40)\end{array}$ & 4 \\
\hline João & 29 & 11 & V.N. Gaia & Nunca teve & 2010 & $\begin{array}{c}\text { Visita } \\
\text { familiares }\end{array}$ & $\begin{array}{l}\text { V.N. } \\
\text { Gaia }\end{array}$ & 2,8 \\
\hline Joaquim & 30 & 5 & Porto & Nunca teve & Nunca & - & & 3,5 \\
\hline José & 48 & 15 & $\begin{array}{l}\text { Póvoa do } \\
\text { Varzim }\end{array}$ & Pescador & 2007 & $\begin{array}{c}\text { Visita } \\
\text { familiares }\end{array}$ & $\begin{array}{c}\text { Póvoa } \\
\text { Varzim } \\
(37)\end{array}$ & 2 \\
\hline Luís & 48 & 1 & Espinho & Nunca teve & 2008 & $\begin{array}{c}\text { Visita } \\
\text { familiares }\end{array}$ & $\begin{array}{c}\text { Espinh } \\
\text { o } \\
(25)\end{array}$ & 2,7 \\
\hline Manuel & 47 & 7 & Trofa & $\begin{array}{c}\text { Empregado } \\
\text { de mesa }\end{array}$ & 2012 & $\begin{array}{l}\text { Pedir na } \\
\text { praia }\end{array}$ & $\begin{array}{c}\text { Espinh } \\
\text { o } \\
(25)\end{array}$ & 3,5 \\
\hline Maria & 42 & 2 & V.N. Gaia & $\begin{array}{l}\text { Empregada } \\
\text { doméstica }\end{array}$ & 2009 & $\begin{array}{c}\text { Visita } \\
\text { familiares }\end{array}$ & $\begin{array}{l}\text { V.N. } \\
\text { Gaia }\end{array}$ & 1,5 \\
\hline Pedro & 58 & 21 & Porto & Litógrafo & $\begin{array}{c}\text { Não } \\
\text { lembra }\end{array}$ & - & & 2,2 \\
\hline Rodrigo & 31 & 2 & $\begin{array}{l}\text { Marco de } \\
\text { Canaveses }\end{array}$ & Nunca teve & 2014 & $\begin{array}{c}\text { Entrevista } \\
\text { trabalho }\end{array}$ & $\begin{array}{c}\text { Santo } \\
\text { Tirso } \\
(29) \\
\end{array}$ & 1,8 \\
\hline Tiago & 34 & 3 & Porto & Nunca teve & 2011 & $\begin{array}{l}\text { Pedir na } \\
\text { feira }\end{array}$ & $\begin{array}{c}\text { Famalic } \\
\text { ão } \\
(39)\end{array}$ & 3 \\
\hline
\end{tabular}

Tabela 2: Doze pessoas em situação de sem teto Fonte: Elaborado pelos autores, 2020.

\section{Arquiteturas precárias}

Encontrar um abrigo (temporário) é um, ou talvez o, aspeto mais crítico da existência das pessoas em situação de sem teto. Tal como Doorn (2010) argumenta, estas 
procuram incessantemente um lugar para pernoitar. A nossa amostra na cidade do Porto revela que à exceção de Rodrigo e António, que mudaram de lugar uma vez, todos os restantes permaneceram na mesma área circunscrita durante o período de tempo em que estiveram em situação de sem teto (Tabela 2). Deste ponto de vista, eles são bastante imóveis. João, por exemplo, vive num raio de 200 metros da Rua Júlio Dinis (Fig. 2) há 11 anos, mudando cinco vezes de abrigo de uma entrada de prédio para outra, até "conquistar" o seu "lugar preferido". Segundo ele, estas entradas são generosas e agradáveis, amplas e abrigadas da chuva e do vento. Com um certo orgulho, João confessou que a sua casa atual - a entrada de uma conhecida pastelaria - é a melhor. Maria e Augusto, vizinhos da praça da Batalha, também "conquistaram” o seu lugar, mas esta "conquista” implica que não se podem afastar muito. Os pertences de Augusto foram roubados mais de uma vez e seu local foi tomado por outras pessoas quando ele estava ausente. Na altura em que falamos com ele, mostrou-se muito relutante em se aventurar para longe. Pedro, António e Manuel, não retiram os seus objetos do seu lugar, mas veem frequentemente o seu lugar ser vandalizado ou roubado. A instabilidade e insegurança é muito presente no seu quotidiano.

Os conceitos de "conquistar" e "possuir" um lugar, foram frequentemente usados pelas pessoas em situação de sem teto, o que está conforme observações de Snow e Mulcahy (2001). O espaço público ou privado pode ser apropriado por pessoas em situação de sem teto, comportando um sentimento de pertença e quase propriedade. José, por exemplo, referiu-se ao seu lugar como casa - nas suas palavras, o "seu domínio" tendo mesmo um tapete verde na entrada. António e Manuel fizeram uma pequena horta onde cultivam alguns legumes. O seu sentimento de pertença é forte, e o cuidado com este ínfimo pedaço de terra ajuda-os não só no sentido material, mas também na autoestima e na construção de um sentimento permanente de casa (SHEEHAN, 2010). Essa prática de inscrição é, sem dúvida, parte de um importante mundo afetivo das pessoas em situação de sem teto, e atua contra uma visão dominante destes como pessoas urbanas invisíveis. Também sinaliza a existência de mundos de esperança, como Cloke, May e Johnson (2010) identificaram.

As relações cordiais com os vizinhos (proprietários ou trabalhadores de espaços comerciais; locais) revelaram-se críticas, sobretudo para José, uma vez que a sua casa é vigiada pelo segurança do edifício em cuja entrada vive. Devido à generosidade dos locais, António e Manuel conseguiram substituir a sua pequena tenda por um barracão de madeira, coberto por cobertores e plástico. Puxaram eletricidade de um poste público 
e, com uma televisão oferecida por um conhecido, assistem aos quatro canais de televisão pública. Também conseguiram um leitor de vídeo, um pequeno frigorífico, uma torradeira e um fogão, que lhes permite guardar alguns alimentos e preparar refeições simples. Num velho carrinho de bebé adaptado, António transporta alimentos, quaisquer materiais que encontre, recipientes de água para a sua higiene e uma fotografia emoldurada do filho. Essas ações ilustram vários processos habilidosos e criativos. $\mathrm{Na}$ verdade, vários estudos demonstraram como as pessoas em situação de sem teto podem ser criativas, ao negociar restrições e criar novas formas de viver em ambientes hostis (HODGETTS et al 2008; JOCOY e DEL CASINO 2010; SHEEHAN 2010).

As restantes oito pessoas em situação de sem teto vivem em locais ainda mais precários. A maioria deles vive em ruas movimentadas, usando as entradas das lojas como abrigo. Cobertores e cartões são os materiais mais utilizados. Duas pessoas usavam cartões oferecidos pela Universidade Católica, no contexto de um projeto de consciencialização sobre a importância dos materiais precários para as pessoas em situação de sem teto, pois muitas vezes são levados à noite pelos serviços de limpeza municipais. Nesses cartões pode-se ler "Cuidado! Esta é a minha casa. Não a leves. Não a destruas". Francisco, João, Luís e Rodrigo escondem os seus pertences durante o dia nos jardins próximos ou noutros cantos escuros. É uma tarefa diária, um processo cansativo que consome tempo e energia. Maria, Joaquim, Augusto e Tiago, tal como tantas outras pessoas em situação de sem teto, não se afastam para longe, pedindo sempre a alguém para vigiar os seus pertences (DOORN, 2010).

\section{Vida quotidiana possível}

A higiene pessoal é uma tarefa desafiadora para as pessoas em situação de sem teto. Após 15 anos como sem abrigo, José mostrou-nos com orgulho como tem acesso a uma torneira de água privada. A menos que as temperaturas sejam muito baixas, ele consegue-se lavar diariamente. António, Manuel e Luís enchem garrafões de plástico de 5 litros em bebedouros públicos e lavam-se em espaços mais reservados. Esta é uma rotina semanal, pois carregar os garrafões é difícil e demorado. João, que mora na mesma rua há 11 anos, conhece os seguranças de um centro comercial próximo, e estes permitem que ele use a casa de banho privativa. As outras sete pessoas entrevistadas usam as instalações de instituições sociais. Só Pedro paga $1 €$ três vezes por mês, para usar uma lavandaria de uma instituição social próxima. Nenhum deles usa balneários públicos, pois 
já tiveram experiências, ou ouviram falar, de roubos, e consideram estes locais como tendo pouca privacidade.

Usar a casa de banho durante o dia também é um desafio quotidiano. Todos os entrevistados dependem de diligências e laços sociais para usar uma casa de banho em cafés ou outros estabelecimentos comerciais, mesmo não fazendo compras. As suas capacidades de negociação e articulação com regras formais e informais, e com uma série de diferentes 'guardiões' (ver também CLOKE, MAY e JOHNSON, 2008), tornam-se fundamentais. Estes laços sociais restringem fortemente a mobilidade, pois os moradores de rua sabem que, se estiverem longe dos quarteirões onde são conhecidos, podem ser impedidos de usar uma casa de banho. Paradoxalmente, nos últimos 20 anos, a par do aumento do número de sem abrigo, o número de casas de banho públicas em funcionamento no Porto (bem como noutras cidades), diminuiu radicalmente. Com exceção de Francisco, João e José, todos os outros nove entrevistados deitam fora as suas roupas sempre que conseguem novas, principalmente as fornecidas por instituições sociais. Francisco vai semanalmente aos Serviços de Assistência Organizações de Maria, organização católica de solidariedade privada, que dispõe de uma lavandaria social de baixo custo. João recorre a um casal que recebe as suas roupas às sextas-feiras, devolvendo-as já lavadas na semana seguinte. José, como já foi referido, tem acesso a uma torneira e a um espaço seguro para pendurar a roupa a secar. Comer depende de dois fatores principais. Em primeiro lugar, do dinheiro que os entrevistados conseguem recolher durante o dia. Em segundo lugar, da assistência prestada pelas várias instituições sociais. Só José e Pedro não recorrem às refeições dos grupos profissionais e voluntários, alegando que não gostam da comida. António e Manuel compram comida num supermercado e cozinham no fogão que têm. Com o aprofundar da crise financeira de 2008, muitas pessoas passaram a recorrer a estes grupos profissionais e voluntários, o que às vezes resulta em grupos bastante grandes à noite. Esta agravamento repete-se agora em 2020, com o agravamento social e económico gerado pela pandemia.

Há quase trinta anos, Wolch et al. (1993: 159) sugeriram que apesar das pessoas em condição de sem teto serem frequentemente referidos como "vagabundos", "errantes" ou "transitórios", e sendo "comumente caracterizados como altamente móveis", vivem quotidianos espacialmente muito restritos. Apesar de não terem casa, ou qualquer lugar físico que as amarre a um lugar, a liberdade de movimento é uma utopia. Esta é de fato uma questão complexa e vários estudos têm mostrado que os moradores de rua têm um raio de ação espacialmente muito limitado (JACKSON, 2012; SMITH, 1992; WOLCH 


\section{1:}

et al, 1993). As 12 pessoas em condição de sem teto entrevistadas, têm uma geografia estruturada em torno de 4 lugares principais. Primeiro, os locais específicos onde grupos profissionais ou voluntários fornecem alimentos e roupas (Fig. 1); em segundo lugar, o seu abrigo, que é escolhido em função da localização anterior; em terceiro lugar, o CAT (Centro de Apoio ao Toxicodependente), que frequentam diariamente; e, por último, o local onde estacionam automóveis, que é principal fonte de rendimento (Figs. 3 e 4).

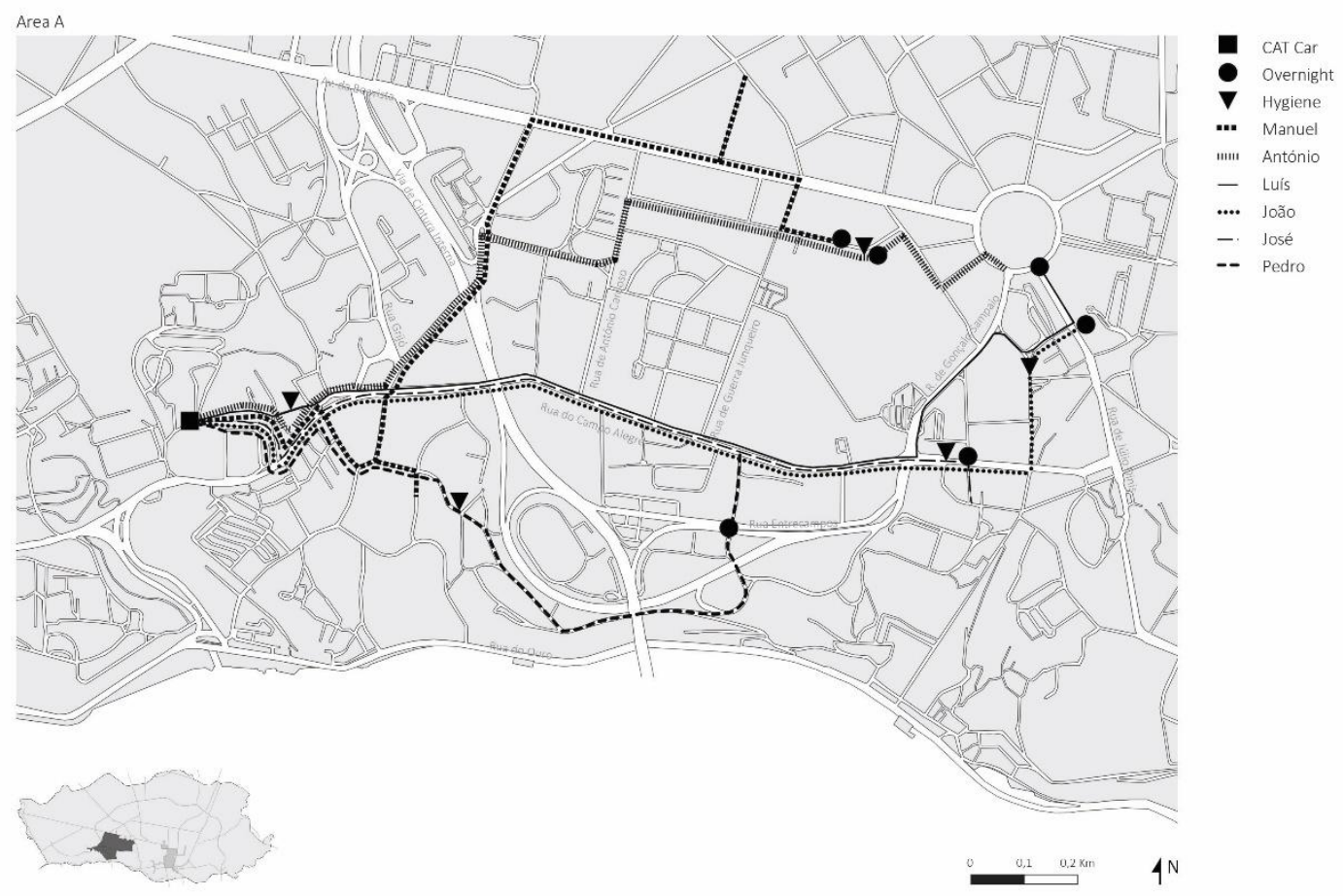

Figura 3: Rotas diárias - Área A

Fonte: Rui Pereira, 2020 


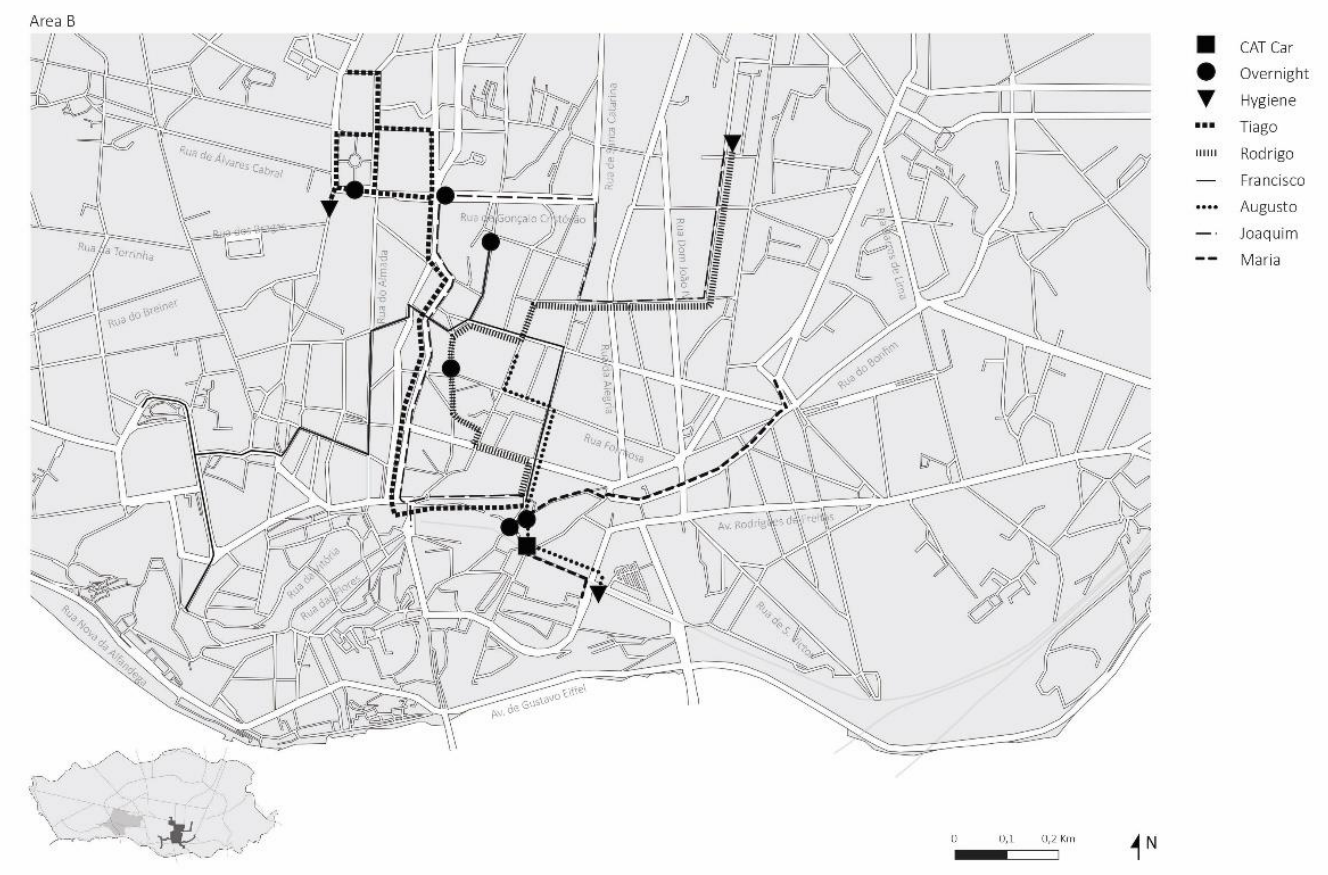

Figura 4: Rotas diárias - Área B

Fonte: Rui Pereira, 2020.

Como já mencionamos, os grupos profissionais e voluntários que fornecem alimentos e roupas constroem uma geografia particular. As suas rotas e paragens sobrepõem-se consideravelmente, havendo uma concentração no centro da cidade. Embora a localização das pessoas em condição de sem teto seja a razão dessa geografia, ela reforça a necessidade das pessoas em condição de sem teto viverem no centro. Todos os entrevistados são toxicodependentes (heroína, cocaína ou crack), estando envolvidos em programas de reabilitação que usam metadona, e que deve ser administrada diariamente. Assim, todos frequentam diariamente a unidade móvel do CAT, às vezes duas vezes ao dia. A sua localização é chave para seus movimentos diurnos. Na área de estudo A, a unidade móvel CAT encontra-se estacionada em Lordelo do Ouro (Rua João de Barros); na área de estudo B, localiza-se no centro da cidade (Baixa, praça da Batalha). Pelas nossas conversas, estas visitas regulares ao CAT são também momentos sociais, onde as pessoas em situação de sem teto conversam umas com as outras, com outras pessoas em tratamento, e também com assistentes sociais.

Metade dos entrevistados ajuda a estacionar automóveis na cidade. Dependendo do tempo que passam nesta atividade (3-6 horas por dia), podem ganhar entre $10 €$ e $25 €$ por dia. Os parques de estacionamento onde exercem esta atividade (Agramonte ou 
Gonçalo Cristóvão, por exemplo) localizam-se a menos de 500 metros de onde residem. Há uma diferença clara entre aqueles que vivem na área $\mathrm{A}$ e aqueles que vivem na área B, pois a primeira área tem mais parques ao ar livre, enquanto a segunda área, no centro da cidade, tem mais parques fechados e menos estacionamento na rua. Ao mesmo tempo, no centro da cidade as pessoas em situação de sem teto disseram-nos que sentiam que precisavam de proteger os seus haveres, por isso optam por pedir nas proximidades. Ajudar no estacionamento de automóveis não é uma atividade diária contínua e é fragmentada pela necessidade de ir ao CAT (uma ou duas vezes ao dia) e por outras atividades. Uma simples viagem ao CAT pode demorar muito. Ao falar com os entrevistados sobre o estacionamento de automóveis, é quase inevitável ouvir histórias de furtos de telefones móveis, arranhões em carros e outros crimes menores, que constroem um estereótipo das pessoas em situação de sem teto como marginais e suspeitas, e que devem ser entendidos no contexto de processos da construção do "outro" em espaços urbanos (SIBLEY 1995). Pedro foi acusado de roubo enquanto ajudava a estacionar automóveis na área onde um automóvel foi roubado. Rodrigo é acusado de arranhar automóveis e Joaquim foi até agredido por dois jovens neste contexto de permanente suspeição.

O local de higiene também dita alguns movimentos regulares, mas quase nenhum implica grandes desvios do percurso abrigo-CAT (apenas Joaquim e Rodrigo caminham cerca de $1 \mathrm{~km}$ em sentido diferente do CAT), pelo que não parece configurar uma mobilidade diferente daquela produzida pelas quatro categorias principais já identificadas. Todos, exceto dois dos entrevistados, se deslocam a pé, o que está de acordo com outros estudos (HAMMARBERG, 2010; DOORN, 2010). José, que raramente se aventura para longe do seu abrigo, vai de autocarro ao CAT, duas vezes ao dia, e Manuel vai de bicicleta para todo o lado. Excetuando Francisco, que percorre $4 \mathrm{~km}$ por dia, Manuel é, juntamente com Joaquim, quem percorre maiores distancias diárias: 3,5 km. Observando os seus padrões espaciais, não só é possível dizer que num determinado dia o ponto mais distante que eles se aventuram não é muito longe de seu abrigo, mas também seus padrões diários são repetitivos, pois normalmente usam as ruas que já conhecem, morando numa área muito confinada da cidade. A saída da cidade ocorre apenas em raras ocasiões (tabela 2 ) e pode ser explicada por quatro fatores: a falta de dinheiro inibe os movimentos; a necessidade de vigiar o seu abrigo implica ficar por perto; a falta de motivações específicas exclui qualquer viagem; e, por último, a consciência de uma geografia confinada proporciona uma sensação de segurança. 


\section{4:}

Enquanto apenas Joaquim alegou que não foi a lado nenhum visto que era sem abrigo (Pedro não se lembra) e António e Rodrigo, que saíram da cidade no ano em que os entrevistámos, todos os outros (8) referiram que a última vez que saíram da cidade foi há mais de dois (1), três (2), quatro (1), cinco (1), seis (2) e mesmo sete (1) anos. A maior distância percorrida foi de aproximadamente $130 \mathrm{~km}$, para comparecer a um funeral, e a maioria viajou apenas $25-50 \mathrm{~km}$. Visitar parentes foi o motivo de 5 em cada 10 .

\section{Conclusão}

Este estudo permite-nos estabelecer cinco ideias principais. A primeira é a forte imobilidade das pessoas em situação de sem teto. Por um lado, elas não se podem afastar muito dos seus pertences, e também do seu abrigo, pois os seus escassos haveres podem ser roubados. Por outro lado, elas não têm recursos para se moverem. Ao mesmo tempo, não mostraram qualquer motivação para irem a diferentes lugares - à beira-mar, ao rio, ou fora da cidade. A segunda ideia decorre da primeira e destaca o fato das pessoas em situação de sem teto morarem numa área muito confinada da cidade. Têm um conhecimento profundo de um número limitado de ruas, de edifícios, de muitas rotinas diárias que acontecem nesses espaços e até mesmo um conhecimento detalhado de micro geografias, como maçanetas de portas, pedras ou postes particulares, e formas e atributos de objetos que parecem irrelevantes ou invisíveis para a maioria das pessoas. Embora este artigo não tenha explorado essa dimensão, a maioria dos entrevistados parece estabelecer vínculos fortes com determinados lugares e com a cidade, que funcionam de diversas maneiras. Estes espaços confinados, que incluem os seus abrigos, redes de pessoas e espaços de circulação bem conhecidos, são vividos por muitos como uma espécie de casa, o que nos remete para a ideia de que a casa e o lugar onde moram se configuram, se definem e se constroem, sob as mais diversas manifestações.

A terceira ideia refere-se ao quotidiano das pessoas em situação de sem teto, que é governado por rotinas espaciais específicas. Embora monótonas e com muitos momentos mortos (DOORN, 2010), as suas vidas estão repletas de um conjunto de atividades de "sobrevivência": procurar ou ir buscar comida, estacionar automóveis, frequentar o CAT, assegurar o melhor abrigo procurando cobertores e papelões, participando nas entregas de sopa, e assim por diante. Em conformidade com Doorn (2010), as pessoas em situação de sem teto alternam caminhadas contínuas com longos períodos de espera. A caminhada é feita no conhecido circuito pessoal, e a espera resulta 
do abrigo da chuva e do frio, os melhores horários para ir a uma determinada loja ou café, ou os horários dos prestadores de serviços. Nesse sentido, ainda que o seu quotidiano seja espacialmente circunscrito, as pessoas em situação de sem teto estão em constante movimento. A quarta ideia aponta para a ideia de que as lógicas dominantes não são as de controle social, nem aquelas destacadas pela abordagem punitiva da gestão da falta de habitação, ou mesmo da cidade revanchista. Embora limitada, encontramos apenas mobilidade voluntária e não encontramos nenhuma mobilidade resultante da aplicação da força da lei. A lógica dominante relaciona-se com as ações dos "fornecedores de sopa", dos centros de atendimento aos toxicodependentes e com a configuração e a localização de lojas abandonadas. Finalmente, as pessoas em situação de sem teto com quem conversamos têm uma agência. Por meio das redes pessoais que constroem, acedem a quartos de banho privados, torneiras de água, e estabelecem uma miríade de laços sociais. Essas ações, ou táticas no sentido de De Certeau (1988), são baseadas na confiança, amizade e noutras competências sociais que envolvem a negociação com pessoas e empresas locais.

\section{Agradecimentos}

Gostaríamos de agradecer a Rui Pereira pela produção dos 4 mapas, e sobretudo ao tempo e generosidade das pessoas em situação de sem abrigo para contribuírem para este estudo.

\section{REFERÊNCIAS BIBLIOGRÁFICAS}

BAPTISTA, I. The First Portuguese Homelessness Strategy: Progress and Obstacles. European Journal of Homelessness 7(2): December, 87-107. 2013.

CLOKE, P., MAY, J. e JOHNSEN, S. Swept up lives? Re-envisioning the Homeless City, WileyBlackwell: Chichester. 2010.

ClOKE, P., MAY, J., e JOHNSEN, S. Performativity and affect in the homeless city. Environment and Planning D: Society and Space, 26(2), 241-263. 2008.

CRESSWELL, T. In Place/Out of Place: Geography, Ideology and Transgression, University of Minnesota Press, Minnesota. 1996.

CRESSWELL, T. The tramp in America. Reaktion Books, London. 2001. 
DAVIS, M. Fortress Los Angeles: the militarization of urban space. Variations on a theme park. In Sorkin, M. (Ed.), Variations on a theme park: the new American city and the end of public space (pp. 154-180), New York: Hill \& Wang. 1992.

DE CERTEAU, M. The practice of everyday life. University of California Press, Berkeley. 1984.

DEVERTEUIL, G., MAY, J. e MAHS, J. Complexity not collapse: recasting the geographies of homelessness in a 'punitive' age. Progress in Human Geography, 33(5), 646-666. 2009.

DOORN, L. V. Perceptions of Time and Space of (Formerly) Homeless People. Journal of Human Behavior in the Social Environment, 20(2), 218-238. 2010.

ENIPSA Estratégia Nacional para a Integração de Pessoas Sem-Abrigo 2009-2015. 2009.

ENIPSA Estratégia Nacional para a Integração de Pessoas Sem-Abrigo 2017-2023. 2017.

HAMMARBERG, T. Social Rights and the Implementation of Housing Rights. Homeless in Europe: The Right to Housing - The Way Forward, pp.5-6. 2008.

HARVEY, D. The right to the city. In Lees, L. (Eds.). The Emancipatory City? Paradoxes and possibilities (pp. 236- 240). Londres: Sage. 2004.

HodGeTts, D., STOLTe, O., CHAMBERlain, K., RADley, A., NIKORA, L., NABALARUA, E., e GROOT, S. A trip to the library: Homelessness and social inclusion. Social and Cultural Geography 9(8): 933-953. 2008.

JACKSON, E. Fixed in Mobility: Young Homeless People and the City. International Journal of Urban and Regional Research. 36(4): 725-741. 2012.

JOCOY, C. L. e DEL CASINO, V. J. Homelessness, travel behaviour, and the politics of transportation mobilities in Long Beach, California. Environment and Planning A 42:1943-1963. 2010.

JOHNSEN, S., CLOKE, P. e MAY, J. Transitory spaces of care: serving homeless people on the street. Health \& Place 11: 323-336. 2005.

MITCHELL, D. The Right to the City: Social Justice and the Fight for Public Space. The Guilford Press; London. 2003.

SASSEN, S. (1999). Juxtaposed temporalities: producing a new zone. In C. Davidson (Ed.) Anytime. (pp. 121-42). Cambridge, MA: MIT Press. 
SHEEHAN, R. "I'm protective of this yard": Long-term homeless person's constructions of home place and workplace in a historical public space. Social and Cultural Geography 11(6): 539558. 2010.

SHELlER. M. e URRY, J. The New Mobility Paradigm. Environment and Planning A, 38: 207226. 2006.

SIBLEY, D. Geographies of Exclusion. London: Routledge.1995.

SMITH, N. Contours of Spatialized Politics: Homeless Vehicles and the Production of Geographical scale, Social Text, 33, 54-81. 1992.

SMITH, N. The New Urban Frontier: Gentrification and the Revanchist City. London: Routledge. 1996.

SNOW, D. e MULCAHY, M. Space, Politics, and the Survival Strategies of the Homeless. American Behavioral Scientist, 45, 149- 169. 2001.

URRY, J., e BUSCHER, M. Mobile methods and the empirical. European Journal of Social Theory, 12(1), 99-116. 2009.

WOLCH, J., RAHIMIAN, A. e KOEGEL, P. Daily and Periodic Mobility Patterns of the Urban Homeless. The Professional Geographer, 45 (2), 159-169. 1993.

ZUKIN, S. Landscapes of Power: From Detroit to Disney World. Berkeley: University of California Press. 1991. 